http://jmscr.igmpublication.org/home/ ISSN (e)-2347-176x ISSN (p) 2455-0450

crossref DOI: https://dx.doi.org/10.18535/jmscr/v7i10.67

\title{
Clinical assessment of dermatological manifestations of dengue fever in a tertiary care center of Karimnagar
}

\author{
Authors \\ Dr Sandhya Rani Kakarla ${ }^{1}$, Dr Ramesh Rachakonda ${ }^{2 *}$ \\ ${ }^{1}$ Assistant Professor, Department of Dermatology, Prathima Institute of Medical Sciences, Karimnagar, \\ Telangana \\ ${ }^{2}$ Assistant Professor, Department of Dermatology, Prathima Institute of Medical Sciences, Karimnagar, \\ Telangana \\ *Corresponding Author
}

Dr Ramesh Rachakonda

Rachaconda Skin and Mind Clinic, H. No.6-6-444, Near SBI Bank, Choppadandi Road, Karimnagar-505001 Telangana State, India

Abstract
Background: The changing epidemiology of dengue fevers in terms of strains, severity and geographic
distribution is raising concern in India. Dengue virus infection, the most common and widespread
arthropod-borne viral infection has grown dramatically in the last 50 years globally. Most commonly
adults are affected by dengue, but the pediatric population is more vulnerable.
Method: A hospital-based study was conducted for a period of 2 months (June -July 2019) among 134
cases of dengue fever between the age group of 3 months to 15 years presenting with symptoms \& signs
suggestive of dengue fever as per WHO criteria were recorded and were analyzed in detail with more
emphasis on onset of skin lesions, their morphology, distribution, sites involved and progression in study
area.
Results: About 134 patients with dengue fever were enrolled, $70.1 \%$ were males and $29.9 \%$ were
females. Cutaneous manifestations were present in $50.7 \%$ of patients while mucous manifestation was
seen in 8.9\% of patients. Bleeding manifestations were seen in $28.4 \%$ of cases with petechiae (26.3\%)
was the commonest manifestation.
Conclusion: Though dengue is a systemic illness, more than half of the patients showed cutaneous
involvement and $50 \%$ of patients had an onset of skin rash consistently with fever which can help in
suspecting dengue illness. Thus skin can be involved in various ways in children with dengue fever and
can help diagnose the illness clinically, especially in places with inadequate laboratory support.
Keywords: Dermatological manifestations, Dengue fever, Pediatric age group.

\section{Introduction}

Dengue virus infection, a widespread vector-borne viral infection has increased several folds in the last 50 years across the world ${ }^{[1]}$. According to WHO statistics about half of the population is exposed to the risk of dengue globally. It is endemic in more than 100 countries $^{[2]}$. The changing epidemiology of dengue fevers in terms of strains, severity and geographic distribution is raising concern in India. The recurrent outbreaks of dengue fever have occurred in different parts of the country over the last $10-15$ years. It is caused 
by a mosquito-borne human viral pathogen that belongs to the genus Flavivirus of the family Flaviviridae (single-strand, non-segmented RNA viruses) which is transmitted mainly by the bite of the mosquito Aedes aegypti which is the major vector and the true reservoir for the virus ${ }^{[3]}$. It affects the adults commonly however; the pediatric population is more vulnerable to dengue. Infection with dengue has been broadly classified into three clinical syndromes; there are four dengue serotypes (DEN-1, DEN-2, DEN-3, and DEN-4). Infection with any of the four serotypes can produce a broad range of clinical manifestations including asymptomatic infection, mild flu-like symptoms, and the more severe hemorrhagic fever and dengue shock syndrome, are accompanied by thrombocytopenia that is often fatal ${ }^{[4]}$. The classical presentation of a mild form of DF includes high-grade fever, myalgia, arthralgia, headache, retrobulbar pain and skin rash ${ }^{[5]}$. Several studies had recorded the various cutaneous manifestations such as transient erythema with facial flushing within first 24-48 hour, maculopapular rash or morbilliform rash, ecchymotic and petechial lesion, generalized rash and mucosal lesion which are Conjunctival congestion, lips crusting, and soft palate vesicle in about 50 to $82 \%$ cases of dengue viral infection ${ }^{[6]}$. Skin lesions may be the presenting feature of dengue fever and recognition of distinctive rash of dengue fever can help make rapid diagnosis thus preventing dengue hemorrhagic fever or dengue shock syndrome, both are life-threatening conditions. Very few studies were available concerning the clinical spectrum of dermatological manifestations of dengue fever infection. Further, as best of our knowledge and available literature, there were no studies conducted concentrating mainly on cutaneous manifestations of dengue fever in infants and children. Hence the present study was carried out to study various dermatological manifestations in case of dengue fever among the pediatric population in the study area.

\section{Material and Methods}

A hospital-based study was conducted for a period of 2 months (June -July 2019) among 134 cases of dengue fever between the age group of 3 months to 15 years presenting with symptoms \& signs suggestive of dengue fever as per WHO criteria who attended OPD clinic in Pediatrics department of Prathima Institute of Medical Sciences, Karimnagar. The study protocol was approved by the institutional ethics committee of the institute. The purpose of the study was explained and written and signed informed consent was obtained. A structured and validated questionnaire consisting of the socio-demographic characteristics, housing, and environmental characteristics, and information regarding various dermatological manifestations and various symptoms developed during disease course was administered to 134 patients attending the Pediatrics OPD clinic. A detailed history with an emphasis on fever, the onset of skin lesions \& history of drug intake before the onset of skin lesions noted in detail with the help of a proforma. A complete clinical examination of skin lesions, morphology, distribution, sites involved with the relevant systemic examination was carried out and relevant investigations such as hematocrit, platelet count, and serology were performed as per requirement. Data were entered into an excel spreadsheet and frequencies of various cutaneous findings were noted.

\section{Results}

The socio-demographic characteristics of the respondents are depicted in table 1. A total of 134 cases of dengue fever between the age group of 3 months to 15 years presenting with symptoms \& signs suggestive of dengue fever as per WHO criteria which are serologically confirmed for dengue viral infection were enrolled in the present study. Among 134 confirmed cases of DF 94 (70.1\%) were male and 40(29.9\%) were female. Most of the patients belonged to the age group of $96(71.6 \%) 10-15$ years followed by the age group of $35(26.2 \%) 5-10$ years. About $34(25.4 \%)$ of 
the study sample are residing in rural areas, while $100(74.6 \%)$ were from urban areas. Out of 134 cases, $56(41.8 \%)$ were registered in June and July months $78(58.2 \%)$.

Table-1 Socio-demographic characteristics of cases

\begin{tabular}{|l|c|c|c|}
\hline Variables & & Number & Percentage \\
\hline \multirow{3}{*}{ Age } & $<5 \mathrm{yrs}$ & 3 & 2.2 \\
\cline { 2 - 4 } & $5-10 \mathrm{yrs}$ & 96 & 71.6 \\
\cline { 2 - 4 } & $10-15 \mathrm{yrs}$ & 35 & 26.2 \\
\hline \multirow{2}{*}{ Sex } & Male & 94 & 70.1 \\
\hline \multirow{2}{*}{ Place of Residence } & Female & 40 & 29.9 \\
\hline \multirow{2}{*}{ Month of Registration } & Urban/Urban slums & 100 & 74.6 \\
\cline { 2 - 4 } & Rural & 34 & 25.4 \\
\cline { 2 - 4 } & June & 56 & 41.8 \\
\hline Total & July & 78 & 58.2 \\
\hline \multirow{2}{*}{} & & 134 & 100 \\
\hline
\end{tabular}

Figure 1: showing the number of cases with skin lesions

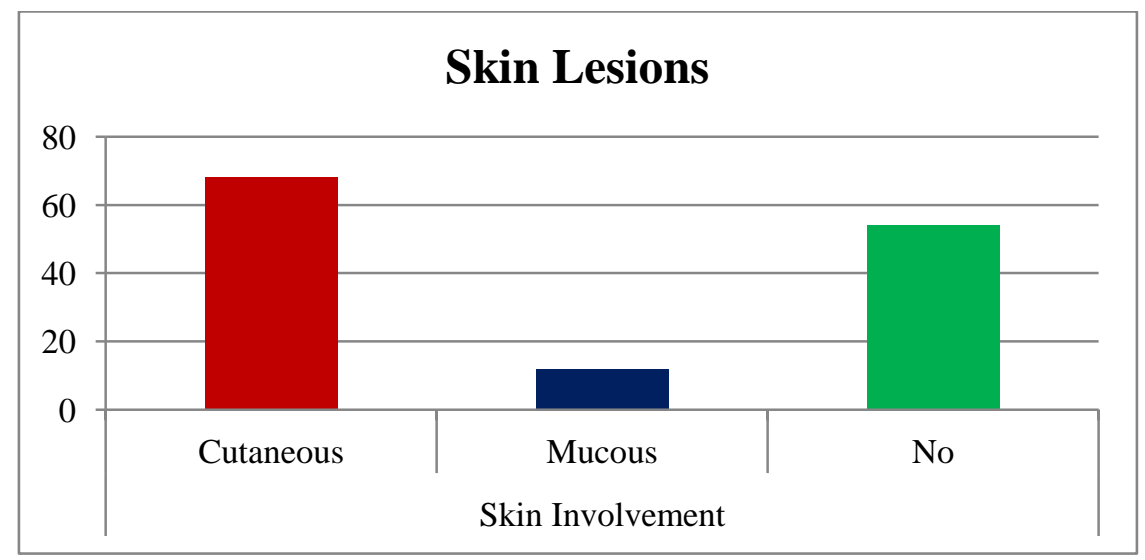

Table $2 \& 3$ shows the various mucocutaneous manifestations developed by the respondents during the disease process. About 68 (50.7\%) patients showed one or more cutaneous manifestation. Skin eruption developed on the same day as fever in 8 cases i.e., (11.8\%) followed by on day 3 about 16 (23.5\%), 28 (41.2\%) cases on day $4,8(11.8 \%)$ cases on day $5(6 \%), 4(5.9 \%)$ cases on day $6,2(2.9 \%)$ cases on day 7, $2(2.9 \%)$ cases on day 8. Regarding the site of rash involvement, $20(29.4 \%)$ cases presented with generalized rash, while rash were localized in 48
(70.6\%) cases. Involvement of various body areas by dengue rash, around $30(44.1 \%)$ cases developed a rash on face, followed by upper limb $8(11.8 \%)$, lower limb $16(23.5 \%)$, abdomen 8 $(11.8 \%)$ and trunk $6(8.8 \%)$ respectively. It was observed that the most common cutaneous change was flushing $36(52.9 \%)$ followed by macules 20 (29.4 \%) and Purpura 14(20.6 \%). Mucosal involvement is estimated to occur in $12(8.9 \%)$ cases. Lip mucosa was most commonly involved in accounting for $6(50 \%)$ of cases, followed by conjunctival mucosa in $4(33.4 \%)$ cases.

Table 2: Number of days for the development of skin eruption in the cases of study

\begin{tabular}{|l|c|c|c|}
\hline \multirow{4}{*}{$\begin{array}{l}\text { Development of skin } \\
\text { eruptions (n=68) }\end{array}$} & Day 1 & 8 & 11.8 \\
\cline { 2 - 4 } & Day 3 & 28 & 41.2 \\
\cline { 2 - 4 } & Day 4 & 16 & 23.5 \\
\cline { 2 - 4 } & Day 5 & 8 & 11.8 \\
\cline { 2 - 4 } & Day 6 & 4 & 5.9 \\
\cline { 2 - 4 } & Day 7 & 2 & 2.9 \\
\cline { 2 - 4 } & Day 8 & 2 & 2.9 \\
\hline Total & & $\mathbf{6 8}$ & $\mathbf{1 0 0}$ \\
\hline
\end{tabular}


Table 3: Distribution of mucocutaneous manifestation of Dengue fever

\begin{tabular}{|c|c|c|c|}
\hline \multirow{2}{*}{$\begin{array}{l}\begin{array}{l}\text { Distribution } \\
(n=68)\end{array} \\
(n=f\end{array}$} & Generalized & 20 & 29.4 \\
\hline & Localized & 48 & 70.6 \\
\hline \multirow{5}{*}{$\begin{array}{l}\text { Site of involvement of } \\
\text { rash }(n=68)\end{array}$} & Face & 30 & 44.1 \\
\hline & Upper limb & 8 & 11.8 \\
\hline & Lower limb & 16 & 23.5 \\
\hline & Trunk & 6 & 8.8 \\
\hline & Abdomen & 8 & 11.8 \\
\hline \multirow{10}{*}{$\begin{array}{l}\text { Type of skin lesion } \\
\text { ( Multiple responses) }\end{array}$} & Flushing & 36 & 52.9 \\
\hline & Macules & 20 & 29.4 \\
\hline & Papules & 12 & 17.6 \\
\hline & Maculopapular & 10 & 14.7 \\
\hline & Petechiae & 10 & 14.7 \\
\hline & Purpura & 8 & 11.8 \\
\hline & Ecchymosis & 5 & 7.4 \\
\hline & Eschar & 2 & 2.9 \\
\hline & Desquamation & 6 & 8.8 \\
\hline & Necrotizing fasciitis & 1 & 1.5 \\
\hline \multirow{4}{*}{$\begin{array}{l}\text { Site of } \quad \text { mucosal } \\
\text { involvement } \\
(n=12)\end{array}$} & Lips & 6 & 50 \\
\hline & Conjunctiva & 4 & 33.4 \\
\hline & Palate & 1 & 8.3 \\
\hline & Tongue & 1 & 8.3 \\
\hline
\end{tabular}

Table 4 presents the various symptoms and signs developed in dengue fever patients. The most common cardinal symptom was fever present in almost all patients. Vomiting was seen in 74 $55.2 \%$ of the cases. This was followed by a pain abdomen in $4231.3 \%$ of the cases and headache in the same number of cases. Convulsion and abdominal distension were the least seen in 2 cases $(1.5 \%)$. Necrotizing fasciitis was noted only in one case in the study area. The clinical signs elicited were hepatomegaly noted in 24 (18\%) of total cases, hepatomegaly was associated with splenomegaly in $10(7.5 \%)$ cases, $6(4.5 \%)$ cases had lymphadenopathy.

Table 4: Distribution of symptoms and signs of Dengue fever among respondents

\begin{tabular}{|l|c|c|}
\hline Variables & Number (134) & Percentage \\
\hline Fever & 134 & 100 \\
\hline Vomiting & 74 & 55.2 \\
\hline Pain abdomen & 42 & 31.3 \\
\hline Headache & 34 & 25.4 \\
\hline Arthralgia & 8 & 6.0 \\
\hline Convulsion & 2 & 1.5 \\
\hline Abdominal distention & 2 & 1.5 \\
\hline Cough & 14 & 10.4 \\
\hline Loose stools & 10 & 7.5 \\
\hline Lower limb edema & 4 & 3.0 \\
\hline Purpura fulmaninas & 10 & 7.5 \\
\hline Necrotizing Fasciitis & 1 & 0.7 \\
\hline Itching & 8 & 6.0 \\
\hline Hepatomegaly & 24 & 18 \\
\hline Splenomegaly & 10 & 7.5 \\
\hline Lymphadenopathy & 6 & 4.5 \\
\hline
\end{tabular}

Table 5 Bleeding was noted in $38(28.4 \%)$ of cases. The skin was the most common site of bleeding noted in form of Petechiae 10 (26.3\%), Purpura $8(21.1 \%)$ and ecchymosis $5(13.2 \%)$ followed by hematemesis in $7(18.4 \%)$ of cases.
Other manifestations are bleeding gums that were noticed in 5(113.2\%) and epistaxis 2(5.3\%). Conjunctival hemorrhage was seen only in 1 $(2.6 \%)$ case. 
Table 5: Distribution of bleeding manifestations among respondents

\begin{tabular}{|l|c|c|}
\hline Bleeding manifestations & Number & Percentage \\
\hline Petechiae & 10 & $26.3 \%$ \\
\hline Purpura & 8 & $21.1 \%$ \\
\hline Ecchymoses & 5 & $13.2 \%$ \\
\hline Bleeding gums & 5 & $13.2 \%$ \\
\hline Hematemesis & 7 & $18.4 \%$ \\
\hline Epistaxis & 2 & $5.3 \%$ \\
\hline Conjunctival hemorrhage & 1 & $2.6 \%$ \\
\hline Total & 38 & $28.4 \%$ \\
\hline
\end{tabular}

Table-6 depicts the bleeding skin manifestation with rash and it was observed from the table that most of the bleeding skin manifestations such as Purpura, Petechiae, ecchymosis, and epistaxis were seen when platelet count was less than
50,000 cells / cumm. Mucosal bleeding (epistaxis, gum bleeding, and hematemesis) were observed when the platelet count was below 30000 cells/cumm. None of the patients was presented with melena and hematuria in the present study.

Table 6: Bleeding skin manifestations with rash depending on platelet count

\begin{tabular}{|l|c|c|c|c|c|c|c|}
\hline Platelet count & Rash & Petechiae & Purpura & Ecchymosis & Bleeding gums & Epistaxis & Hematemesis \\
\hline$<50,000$ & 0 & 2 & 3 & 2 & 2 & 1 & 2 \\
\hline $50,000-1,00,000$ & 42 & 6 & 4 & 3 & 3 & 1 & 5 \\
\hline$>1,00,000$ & 35 & 2 & 1 & 0 & 0 & 0 & 0 \\
\hline
\end{tabular}

\section{Discussion}

The involvement of younger age groups in Dengue and an increase in the frequency of epidemics are indications of a higher incidence of infection. Early diagnosis is essential to reduce the mortality \& morbidity related to the disease. Recognition of cutaneous features is important as dengue fever may progress to life-threatening dengue hemorrhagic fever or dengue shock syndrome. Hence the present study was undertaken to assess the dermatological manifestations in the pediatric population attending tertiary care centers in the study area. A total of $n=134$ dengue fever cases were enrolled for the study of which $70.1 \%$ were male and $29.9 \%$ were female. The present study showed the incidence of dengue fever was more among males with $\mathrm{M}$ : $\mathrm{F}$ ratio being $2.5: 1$, probably more outdoor activities seen in boys ${ }^{[7]}$. Full body covered dresses generally worn by females may be another cause for fewer incidences. Although a high incidence of dengue fever has been described in children, there are very few studies done exclusively on them. In the present study, $71.6 \%$ of the respondents were between the age group of
5-10 years. The age group affected was lower in this study compared to the previous Indian studies $^{[8]}$. This supports the view that the incidence of Dengue fever is on the rise in India. Although there are relatively fewer reported cases among children, higher rate fatality has been observed in this age group ${ }^{[9]}$. A study conducted by Pothapregada et al; found that the mean age of presentation was 6.9 years and 6-12 years were the most commonly affected age group (62.0\%) which was consistent with the present study findings ${ }^{[10]}$. A similar study conducted by Gurdeep et al; has shown $<6$ years of age to be the most commonly affected age group ${ }^{[11]}$. In the present study, $74.6 \%$ of total cases were residing in the urban area $\& 25.4 \%$ from the rural area, which is consistent with other studies worldwide ${ }^{[12-14]}$.

Regarding the pattern of cutaneous manifestation, it was found that cutaneous findings are prominently seen in patients of dengue fever and have been reported to occur in $50.7 \%$ of patients. In the majority (41.2\%) the cutaneous manifestations were noted on day 3 . The rash was localized in $70.6 \%$ \& generalized in $29.4 \%$ of cases. Petechiae \& ecchymosis were noted in 
$14.7 \% \& 7.4 \%$ respectively. Eschar was present in $\mathrm{n}=2$ out of $\mathrm{n}=134$ cases accounting for $2.9 \%$ and these cases went in to develop purpura fulminans. There was one case that had necrotizing fasciitis along with dengue fever which can be an accidental association. A study conducted by Kumarasinghe et al; found that the time taken for skin manifestations showed a wide time range but in the majority, the rash appeared between days 3 and 5, the meantime being 4.07 days. When the pediatric population is considered separately the meantime was 5.12 days ${ }^{[15]}$. In the current study, mucosal involvement is seen $8.9 \%$ of cases of DF. Lip mucosa was most commonly involved accounting for $50 \%$ of cases, closely followed by conjunctival mucosa in $33.4 \%$ cases. While in a study conducted by Seetharam et $\mathrm{al}^{[5]}$ have showed that mucosal involvement is seen $15-30 \%$ cases of DF, which includes conjunctival congestion, crusting of lips, small vesicle or ulceration on soft palate, crusting or drying of tongue whereas in another study conducted by Thomas et al; ${ }^{[6]}$ found the mucosal involvement was $29.8 \%$ of patients, with involvement of conjunctiva, lips, palate, and tongue was $20.9 \%$, $4.8 \%, 2.4 \%$, and $1.6 \%$ respectively. Most of the patients with skin manifestation were asymptomatic, only $4 \%$ cases complained of associated itching. Common clinical findings in the systemic examination were Hepatomegaly (18\%), splenomegaly (7.5\%) and lymphadenopathy $(4.5 \%)$ which were lower compared with other studies. In another study done by Reddy GC et $\mathrm{al}^{[16]}$ found that the anorexia (81.0\%), nausea/vomiting (7 $\left.9 \begin{array}{ll}7 & .0 \%\end{array}\right)$, headache $(5 \mathrm{I} .4 \%)$ and bleeding tendency were common features. In comparison to adults, apart from these symptoms, positive tourniquet test, abdominal tenderness, convalescent rash, pleural effusion and ascites due to plasma leakage as a result of low serum albumin and sodium were also reported and further showed a higher association of bleeding in children, but requirement of transfusion was more in adults compared to children $^{[17]}$.
Bleeding manifestations were seen in $28.4 \%$ of cases and lower in comparison to the previous studies. The most common hemorrhagic manifestations in the current study were Petechiae (26.3\%) and GI bleeding (18.4\%) and similar to the previous studies by Ratageri et al., ${ }^{[18]}$ Hematemesis was reported as the most common manifestations in the study by Narayanan et al., ${ }^{[19]}$ whereas epistaxis was most common in the study by Faridi et al; ${ }^{[20]}$ Prevalence of Melena in previous studies ranged from 46-66.0\%. Hematemesis $(31.20 \%)$ and epistaxis $(52.60 \%)$ were the most common bleeding manifestation reported in other studies. ${ }^{[21]} \mathrm{IgM}$ and $\mathrm{IgG}$ have been extensively used for the diagnosis of DHF. The present study made use of two commercial kits available, namely the MRL ELISA and PanBio ELISA kits, which have shown high degree sensitivity and specificity in the global testing centers and were highly recommended for the purpose. Serology, with clinical presentation and other investigations, formed the mainstay of diagnosis. IgM ELISA has always been one of the sheet anchors for the diagnosis of dengue infection.

\section{Conclusion}

The present study within its own limitations concluded that dengue although a systemic illness, more than $50 \%$ of patients showed cutaneous involvement which may be considered significant. In the current study, the cutaneous rash appeared in fifty percent of patients concurrently with the fever which can help in suspecting dengue illness. We in this study found that there was presence of cutaneous lesions in more than seventy percent of patients which can be useful for diagnosing dengue. The most common manifestation of dengue was flushing seen in $52.9 \%$ of patients. The present study also found that there is no correlation between cutaneous lesions and the mean platelet counts. Bleeding tendency was found in twenty five percent of patients that can be helpful in suspecting dengue clinically. Dermatological manifestations of dengue are very 
important to recognize although they may not be found in all patients. But if identified early it will be useful for early diagnosis and better management of patients.

\section{Conflict of interest: None \\ Source of support: Nil \\ Ethical Permission: Obtained}

\section{References}

1. Khan E, Hasan R. dengue infection in Asia; A Regional concern, Editorial. J Post Graduate Med Inst 2012; 20(1);1-6.

2. Dengue and severe dengue. https://www.who.int/news-room/factsheets/detail/dengue-and-severe-dengue [online Accessed on August 20 2019]

3. Omar L, Gustavo CC, Branco CIC. Mucocutaneous manifestations of dengue. An Bras Dermatol. 2007; 82: 291-305.

4. Lee LK, Thein TL, Kurukularatne C, Gan $\mathrm{VCH}$, Lye DC, Leo YS. Dengue Knowledge, Attitudes, and Practices among Primary Care Physicians in Singapore. Ann Acad Med Singapore 2011;40:533-38.

5. K. A. Seetharam, IADVL Textbook of Dermatology, fourth edition 2015, vol-1; 612-14.

6. Thomas EA, John M, Bhatia A. Cutaneous manifestation of dengue viral infection in Punjab (North India). Int $\mathrm{J}$ Dermatol. 2007; 46: 715-19.

7. World Health Organization. Comprehensive guidelines for prevention and control of Dengue and dengue hemorrhagic fever. http://apps.searo.who.int/pds_docs/B4751. pdf [Accessed on 25 August 2019]

8. Narayanan M, Arvind MA, Thilothammal N, Prema R, Sargunam Rex CS et al. Dengue fever epidemic in Chennai - A study of clinical profile and outcome. Indian Pediatr 2002;39:1027-33.
9. Mahmood K, Jameel T, Aslam HF, Tahir $M$. Incidence of dengue hemorrhagic fever in the local population of Lahore, Pakistan. Biomedica 2009;25:93-96.

10. Pothapregada S, Kamalakannan B, Thulasingham M, Sampath S. Clinically profiling pediatric patients with dengue. $\mathrm{J}$ Global Infect Dis 2016; 8:115-20.

11. Gurdeep SD, Deepak B, Harmesh SB. Clinical profile and outcome of children of dengue hemorrhagic fever in North India. Iran J Pediatr 2008; 18:222-28.

12. Teixeira MG, Barreto ML, Costal MCN, Denize L, Ferreira A, Vasoconcelos PFC et a. Dynamics of dengue virus circulation: a silent epidemic in a complex urban area. Trop Med Int Health 2002;7:757-62.

13. EA Henchal, JR Putnak. The Dengue Viruses. Clin Microbiol Rev 1990; 3(4): 376-96.

14. S. Ahmed, F. Arif, Y. Yahya et al; Dengue fever outbreak in Karachi2006 a study of profile and outcome of children under 15 years of age, Journal of the Pakistan Medical Association 2008; 58(1):4-8.

15. SPW Kumarasinghel, AMSD Eriyagama, W Gunathileke, KPP Wijesuriyaa, L De Silva. Cutaneous manifestations of dengue fever. Sri Lanka Journal of Dermatology 2009;1(3):10-74.

16. Gomber S, Ramachandran VG, Kumar S, Agarwal, Gupta P, Gupta P et al. Hematological observations as diagnostic markers in dengue hemorrhagic fever a reappraisal. Indian Pediatr 2001;38:47781.

17. Reddy GC, Nagendra K. Clinical and diagnostic features of dengue hemorrhagic fever in children. Int $\mathbf{J}$ Contemp Pediatr 2018;5(3):791-97.

18. Rachel Daniel, Raja Mohan, Aby Zachariah Philip. A Study of Clinical Profile of Dengue Fever in Kollam, Kerala, India. Dengue Bulletin 2005; Vol 29: 197-202. 
19. Narayan M, Aravind MA, Thilothammal $\mathrm{N}$, et al. Dengue fever epidemic in Chennai: a clinical profile and outcome. Indian Pediatrics. 2002; 39: 1027-33.

20. Faridi MMA, Aggarwal A, Kumar M, Sarafrazul A. Clinical and biochemical profile of dengue haemorrhagic fever in children in Delhi. Trop Doct. 2008;38 (1):28-30.

21. Kumar R, Tripathi P, Tripathi S, Alokkanodia, VimalaVenkatesh. Prevalence of dengue infection in North Indian children with acute hepatic failure. Ann Hepatol. 2008;7:59-62. 